This is the author's final, peer-reviewed manuscript as accepted for publication. The publisher-formatted version may be available through the publisher's web site or your institution's library.

\title{
Audits and inspections are never enough: a critique to enhance food safety
}

Douglas Powell, Maria Sol Erdozain, Charles Dodd, Katija Morley, Roy E. Costa, Benjamin Chapman

\section{How to cite this manuscript}

If you make reference to this version of the manuscript, use the following information:

Powell, D. A., Erdozain, S., Dodd, C., Morley, K., Costa, R., \& Chapman, B. J. (2013). Audits and inspections are never enough: A critique to enhance food safety. Retrieved from http://krex.ksu.edu

\section{Published Version Information}

Citation: Powell, D. A., Erdozain, S., Dodd, C., Costa, R., Morley, K., \& Chapman, B. J. (2013). Audits and inspections are never enough: A critique to enhance food safety. Food Control, 30(2), 686-691.

Copyright: (c) 2012 Elsevier Ltd.

Digital Object Identifier (DOI): doi:10.1016/j.foodcont.2012.07.044

Publisher's Link: http://www.sciencedirect.com/science/article/pii/S0956713512004409

This item was retrieved from the K-State Research Exchange (K-REx), the institutional repository of Kansas State University. K-REx is available at http://krex.ksu.edu 


\section{Accepted Manuscript}

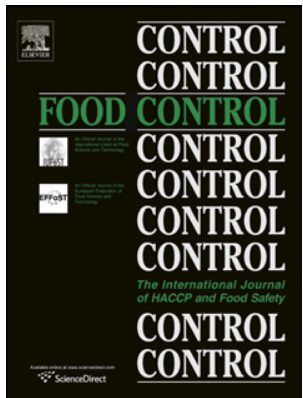

Audits and inspections are never enough: A critique to enhance food safety

D.A. Powell, S. Erdozain, C. Dodd, R. Costa, K. Morley, B.J. Chapman

CONTROL

PII:

S0956-7135(12)00440-9

DOI:

10.1016/j.foodcont.2012.07.044

Reference:

JFCO 2885

To appear in: Food Control

Received Date: 3 April 2012

Revised Date: 17 July 2012

Accepted Date: 24 July 2012

Please cite this article as: PowellD.A., ErdozainS., DoddC, CostaR., MorleyK. \& ChapmanB.J., Audits and inspections are never enough: A critique to enhance food safety, Food Control (2012), doi: 10.1016/ j.foodcont.2012.07.044.

This is a PDF file of an unedited manuscript that has been accepted for publication. As a service to our customers we are providing this early version of the manuscript. The manuscript will undergo copyediting, typesetting, and review of the resulting proof before it is published in its final form. Please note that during the production process errors may be discovered which could affect the content, and all legal disclaimers that apply to the journal pertain. 
1 Audits and inspections are never enough: a critique to enhance food safety

3 Powell, D.A., Erdozain, S., Dodd, C., Costa, R. Morley, K. and Chapman, B.J.

4

5 Douglas Powell

6 Professor, Food Safety

7 Department of Diagnostic Medicine/Pathobiology

8 Kansas State University

9 Manhattan, KS 66506

11 Maria Sol Erdozain

12 Research Assistant

13 Kansas State University

14 Manhattan, KS 66506

$15 \quad 785-323-7501$

17 Charles Dodd

18 cdoddemail@googlemail.com

20 Katija Morley

21 Research Assistant

22 Kansas State University

2322 Karen Ave. Guelph, ON N1G 2N9. 519-362-0101

24 Tija.morley@gmail.com

25

26 Roy E. Costa

27 President

28 Environ Health Associates, Inc

292694 Magnolia Rd

30 Deland Fla 32720

$31 \quad 386-734-5187$

32 Rcosta1@cfl.rr.com

33

34 Benjamin Chapman

35 Assistant Professor

36 Department of 4-H Youth Development and Family \& Consumer Sciences

37 North Carolina State University, NC Cooperative Extension

38 Raleigh, North Carolina

3927616

40

41

42 Keywords: food safety; audit; inspection; culture 
Abstract

Internal and external food safety audits are conducted to assess the safety and quality of food including on-farm production, manufacturing practices, sanitation, and hygiene. Some auditors are direct stakeholders that are employed by food establishments to conduct internal audits, while other auditors may represent the interests of a secondparty purchaser or a third-party auditing agency. Some buyers conduct their own audits or additional testing, while some buyers trust the results of third-party audits or inspections. Third-party auditors, however, use various food safety audit standards and most do not have a vested interest in the products being sold. Audits are conducted under a proprietary standard, while food safety inspections are generally conducted within a legal framework. There have been many foodborne illness outbreaks linked to food processors that have passed third-party audits and inspections, raising questions about the utility of both. Supporters argue third-party audits are a way to ensure food safety in an era of dwindling economic resources. Critics contend that while external audits and inspections can be a valuable tool to help ensure safe food, such activities represent only a snapshot in time. This paper identifies limitations of food safety inspections and audits and provides recommendations for strengthening the system, based on developing a strong food safety culture, including risk-based verification steps, throughout the food safety system.

\subsection{Introduction}

Billions of meals are prepared safely each day throughout the world. The commercial food system relies on audits and inspections to assess the practices and processes used to by food producers at each step in the production chain. Yet when outbreaks of foodborne illness happen, the results can be emotionally, physically and financially devastating to the victims and the businesses involved. Many outbreaks involve firms that have had their food production systems verified and received acceptable ratings from food safety auditors or government inspectors.

Food safety audits and inspections are one activity used to verify that a food producer or individual is following specific guidelines, requirements or rules. Audits involve a "systematic and independent examination to determine whether quality/safety activities and related results comply with planned arrangements and whether these arrangements are implemented effectively and are suitable to achieve objectives" (ANZFA, 2001; ANZFA was later morphed into Food Standards Australia New Zealand). Planned arrangements, as defined by the Australia New Zealand Food Authority are commonly referred to as standards within the food industry. The difference between inspections and audits is that an inspection evaluates "conformity by measuring, observing, testing or gauging the relevant characteristics"(ANZFA, 2001). Audits are one tool to help ensure adherence to recognized regulations and good manufacturing practices. 
An audit of food safety practices, facilities, documentation and written procedures is used to gather information regarding food production and processing practices being followed by a particular producer, identifying areas for improvement and areas that are deficient (ANZFA, 2001). Audit reports, in theory, serve as the "eyes and ears" for an organization buying food from a supplier (Weise, 2010). There are several types of audits, and a variety of audit organizations, each with their own unique or common food safety guidelines.

Self-audits are internal audits performed by a food establishment itself. These businesses usually have a quality assurance team that leads the internal audits. These internal audits may have good potential for reducing risk if the methods followed are those outlined in widely accepted codes and risk assessment guidance documents. The effectiveness of internal audits is also assessed during third-party audits. Second-party audits are audits that a downstream company, or buyer, performs on their supplier. Third-party audits are performed by an outside firm that usually focuses entirely on verification or standard implementation to ensure that a buyer's rules are being followed (Costa, 2010). Third-party audits examine compliance with laws and codes of practice as well as provide "insight into management controls and supervision" (Costa, 2010).

\subsection{The role of audits in food safety}

Third-party audits are one part of a multi-factorial approach to food safety. The popularity of third-party audits has increased corresponding to a shift in food safety governance away from government regulation and inspection towards the development of private food safety standards (Busch, 2011).

Standard setting organizations (e.g. International Organization for Standardization (ISO) and the British Retail Consortium [BRC]) include industry consortia, private voluntary associations and buyers. There are many different food safety standards available to food producers and manufacturers even within a single industry segment. While the various standards are voluntary, demand by buyers essentially makes certification or verification under these standards de facto mandatory for food companies that want to continue to sell their product to major retailers (Busch, 2011). This has created a system for enforcing food safety standards without significantly increasing burden on taxpayers.

In addition, if a company such as Walmart wanted specific standards for a product, even if it exceeded U.S. Food and Drug Administration (FDA) standards, the company would demand that from the auditor -- and get it (Prevor, 2009).

While inspectors play an active role in overseeing compliance, the burden for food safety lies primarily with food producers (GAO, 2008). Inspection efforts, even if 

doubled, would not be enough to make sure every food item is safe. Third party audits provide the data upon which certification and buying decisions are made, and are now a popular choice for retailers who use them to push the responsibility (and costs) for food safety and quality back on to the supplier (Steir, 2009). Audits are an attempt to move beyond inspections that are point-in-time observations of activities and practices. Audits focus on the procedures in place to achieve food safety outcomes and look for evidence that they are being followed and are appropriate and capable of reducing risk. There is also increasing focus on assessment of food safety culture and management commitment to food safety.

Third-party audits also benefit individual companies and supply chains. It has been argued that the best use of third-party audits is to focus on strengthening self-audit methods and operational controls to achieve safer food (Costa, 2010).For some, it is a genuine desire to improve food safety, quality and sanitation or a way to solve/troubleshoot existing problems (Steir, 2009). For others it is a potential marketing advantage or a customer requirement. The effectiveness of these audits may link to the motivation behind the audit. It has been determined that creating a food safety culture is imperative to an effective food safety risk management system (Powell et al., 2011; Yiannas, 2008). Companies with a strong food safety culture may be more likely to obtain a third party audit because they want to improve operations, not just because of customer demand. Companies with a strong food safety culture are also likely to use audit results as guidance and opportunity to improve their practices. Audits -- firstsecond- or third-party -- are another tool for companies to enhance safe food production.

What is not clear is the role of third party audits in reducing the risk of contaminated food reaching the marketplace and the ability of auditors to identify problems or highrisk operations. The utility of third party audits has been examined in other industries as well. A 10-year study on workplace safety on U.S. railroads found that high audit scores partially correlated with improved legislative compliance but did not necessarily correspond to improved safety performance (Peterson, 2001). This indicated there were problems somewhere in the system and that the audit process was not necessarily valid for that industry.

\subsection{Limitations of audits}

Audit systems, in their current form, have limitations in improving food safety. There are no current empirical evaluations that look at the correlation between audit scores and foodborne illness outbreaks but there is a long and storied history of food safety failures involving third-party audits.

Third-party audits are analogous in many ways to regulatory municipal inspections of foodservice operations: the effectiveness of both audits and inspections is driven largely 
173 by observational judgment and consistency of the inspector or auditor. Foodservice

174 inspection is a cornerstone of local public health, yet inspection scores can be poor

175 predictors of foodborne illness. Jones and colleagues (2004) examined over 160,000

176 inspections in Tennessee over seven years and found no difference between scores of

177 foodservices associated with outbreaks and those that were not. Similar results were

178 previously found in Miami-Dade county (Cruz et al., 2001). In Massachusetts,

179 researchers found that jurisdictions had different inspection criteria, and even within a

180 given jurisdiction, a risk to one inspector may not be a risk to another (DeNucci 2007).

Many foodborne illness outbreaks have been linked to farms, processors and retailers that went through some form of audit certification. The January 2009 outbreak of Salmonella Typhimurium linked to the Peanut Corporation of America (PCA) has been frequently cited as an example of a failure in the third party auditing system (Busch, 2011; Steir, 2009; Moss and Martin, 2009). In January, 2009 PCA recalled over 3,900 peanut butter and other peanut-containing products from more than 350 companies (FDA, 2009b), 691 people were sickened and nine died across 46 U.S. states and in Canada (CDC, 2009a).

Moss and Martin (2009) reported in the New York Times that an auditor with AIB was responsible for evaluating the safety of products produced by PCA. The peanut company knew in advance when the auditors were arriving. "The overall food safety level of this facility was considered to be: SUPERIOR," the auditor concluded in his March 27, 2008, report for AIB. A copy of the audit was obtained by the Times. AIB was not alone in missing the trouble at the PCA plant in Blakely, Georgia. State inspectors also found only minor problems. This outbreak and others highlight some of the limitations of both third party audits and government inspections which are included in Table I below.

Table I - Limitations of Third Party Audits

\begin{tabular}{|l|l|l|}
\hline $\begin{array}{l}\text { Audit } \\
\text { Limitations }\end{array}$ & Summary & Example \\
\hline $\begin{array}{l}\text { A snapshot } \\
\text { in time }\end{array}$ & $\begin{array}{l}\text { Audits and inspections remain point-in-time } \\
\text { assessments that represent a small fraction of } \\
\text { food production time and volume. If conducted } \\
\text { properly and the results acted upon, audits can } \\
\text { reveal strengths and weaknesses in a food safety } \\
\text { program, but cannot guarantee future } \\
\text { performance. Further, auditors can only examine } \\
\text { what a company provides, although skilled } \\
\text { auditors know what to ask for and may be able } \\
\text { to identify clues to systemic problems. }\end{array}$ & $\begin{array}{l}\text { PCA outbreak, a federal team of } \\
\text { investigators later uncovered a } \\
\text { number of alarming signs at the } \\
\text { peanut plant including testing } \\
\text { records from the company itself } \\
\text { that showed Salmonella in its } \\
\text { products as far back as June 2007 } \\
\text { (Martin, 2009) }\end{array}$ \\
\hline
\end{tabular}




\begin{tabular}{|c|c|c|}
\hline $\begin{array}{l}\text { Reliance on } \\
\text { an effective } \\
\text { standard }\end{array}$ & $\begin{array}{l}\text { The audit is only as effective as the standard } \\
\text { against which the practices are being measured. } \\
\text { Standards must be evidence-based, designed to } \\
\text { address the commodity/product specific risks } \\
\text { and practices and responsive to changing } \\
\text { industry practices and new science as it becomes } \\
\text { available. }\end{array}$ & $\begin{array}{l}\text { Cantaloupe outbreak, July } 2011 . \\
\text { Previous research had focused on } \\
\text { Salmonella and current industry } \\
\text { standards may not be robust } \\
\text { enough to address risk from } \\
\text { Listeria. }\end{array}$ \\
\hline $\begin{array}{l}\text { Effective } \\
\text { audit tool }\end{array}$ & $\begin{array}{l}\text { The audit tool (or audit checklist) must be } \\
\text { valid. There is no scientific basis for } \\
\text { certification/validation in audits (Mahshie, } \\
\text { 2009). There is high variability in the quality } \\
\text { and reliability of audits and many different } \\
\text { types of audit tools that vary in length, } \\
\text { complexity, and style. A firm may pass some } \\
\text { audits but still have a food safety risk factor }\end{array}$ & $\begin{array}{l}\text { Salmonella in eggs, Iowa, } 2010 \text {, } \\
\text { lead to 2,000 illnesses and the } \\
\text { recall of } 500 \text { million eggs. DeCoster } \\
\text { received a superior rating from AIB } \\
\text { International, despite audit reports } \\
\text { that are typically 10-20 pages and } \\
\text { consider over } 300 \text { elements (AIB } \\
\text { International, 2007). }\end{array}$ \\
\hline $\begin{array}{l}\text { Auditor } \\
\text { competence }\end{array}$ & $\begin{array}{l}\text { Audits require more than just a checklist, they } \\
\text { require paying attention and thinking. The } \\
\text { individual ability of an auditor has a significant } \\
\text { impact on the outcome of the audit, most third- } \\
\text { party audits look for objective evidence to assess } \\
\text { compliance, but effective auditors must be able } \\
\text { to assess risk, particularly in unique situations } \\
\text { and synthesize the information provided to } \\
\text { determine effectiveness of the food safety } \\
\text { management system }\end{array}$ & $\begin{array}{l}\text { In the aftermath of the PCA } \\
\text { outbreak, the competency of both } \\
\text { the auditor and the auditing firm } \\
\text { were criticized. The auditor of the } \\
\text { PCA facility was an experienced } \\
\text { auditor but was an expert in fresh } \\
\text { produce and was not aware that } \\
\text { peanuts were susceptible to } \\
\text { Salmonella (Moss and Martin, } \\
\text { 2009) }\end{array}$ \\
\hline$A u d$ & $\begin{array}{l}\text { ough to } \\
\text { products. } \\
\text { h different } \\
\text { cheapest } \\
\text { with less } \\
\text { dces cost for } \\
\text { reduces the } \\
\text { ts of a } \\
\text { ossibility of } \\
\text { n- }\end{array}$ & $\begin{array}{l}\text { On June } 28,2007, \text { Veggie Booty } \\
\text { snack food was linked to an } \\
\text { outbreak of Salmonella. The plant } \\
\text { that made Veggie Booty had } \\
\text { received a rating of "excellent" } \\
\text { from AIB International, raising } \\
\text { questions about the efficacy of } \\
\text { auditors and audits, which, in this } \\
\text { case and others, did not extend to } \\
\text { ingredient suppliers (Moss \& } \\
\text { Martin, 2009). }\end{array}$ \\
\hline $\begin{array}{l}\text { Conf } \\
\text { Inte }\end{array}$ & \multicolumn{2}{|c|}{$\begin{array}{l}\text { Almost all food producers/retailers require their suppliers to pay for their own audits. } \\
\text { A company receiving a poor audit may be unwilling to hire that auditor again. Even } \\
\text { with safeguards in place, auditing bodies still must rely on the honesty of their } \\
\text { auditors to declare potential conflicts }\end{array}$} \\
\hline Follow-up & \multicolumn{2}{|c|}{$\begin{array}{l}\text { Auditors have no legal authority and cannot demand records, embargo products or } \\
\text { close an operation (Costa, 2011). Neither the auditor nor the audited company is } \\
\text { required to report non-compliances, even automatic failures, to regulatory agencies. If } \\
\text { the buyer does not review the audit report closely, which is often the case (Prevor, } \\
\text { 2011a), they may never know that their supplier had a serious non-conformance. }\end{array}$} \\
\hline
\end{tabular}

203 In response to some of the criticisms around third party audits and standards and the 204 growing number of private standards with no real oversight over their development, 
the Global Food Safety Initiative (GFSI) was launched in May, 2000. GFSI is a non-profit foundation managed by the consumer goods forum (GFSI, 2012). GFSI is a benchmarking system where "all recognized schemes have a common foundation of requirements which should provide consistent results, in regard to the common requirements applied during the audit, but the benchmarked schemes cannot be considered as equal" (GFSI, 2012). One objective of the initiative is to reduce costs within the system by reducing the number of different audits a firm requires for their different customers. The success of the GFSI approach has not been evaluated to date.

\subsection{Improving audits and inspections}

Food safety auditors and inspectors are an integral part of the food safety system, and their use will expand in the future, for both domestic and imported foodstuffs.

Supporters of third-party audits argue this type of audit augments the efforts of food regulatory agencies, such as FDA, the Canadian Food Inspection Agency (CFIA), and others.

Auditing can be helpful, in theory. Audit reports, are only useful if the purchaser or food producer them reviews the results, understands the risks addressed by the standards and makes risk-reduction decisions based on the results. From past examples, there appears to be a disconnect between what auditors provide (a snapshot) and what buyers believe they are doing (a full verification of product and process).

Third-party auditing can also assist regulatory agencies by providing the extra assessment and data a regulatory agency might not be able to collect as often as required - but only if the data is shared with regulatory agencies. Audits and inspections can assist in the development of a food safety culture by dictating criteria for the sale of goods (Acheson, 2010). The training component for employees is another use of audits in the daily implementation of food safety practices (AIB International, 2007). Third-party audits also provide "thousands of checks and balances to the food supply system with no direct cost to taxpayers" (AIB International, 2007). However, theory and practice can differ.

Critics see many problems with the general way third-party audits are currently conducted and have described them as the equivalent of "mail-order diplomas" (Moss \& Martin, 2009). As far as being the "eyes and ears" for a company buying from the audited supplier, many problems are apparently missed during visits (Weise, 2010). Heavy reliance on prescriptive checklists may increase auditor consistency, allow for cost savings on training but also reduces their ability to assess risk. This ultimately results in a pool of auditors that are poorly qualified to assess the risks associated within individual operations. It is imperative for the food industry to aggressively take 
corrective actions and make third-party audits and inspections more meaningful, more accurate, and to fully enhance the safety of consumers.

Good auditors look beyond what is on their checklist and can synthesize the various pieces of information they get to put together a clear picture of whether the operation is doing what they say they are doing. Certification bodies must also embrace a food safety culture, ensuring their auditors have the appropriate training, oversight, knowledge and support.

In an effort to improve the third party audit system, FDA is working to establish accreditation programs under a new food safety law, to insure the quality of audits (Karst, 2011). FDA is also trying to make audit results accessible so they can analyze the results for effectiveness and reliability (Karst, 2011). FDA released guidance for industry in 2009 regarding voluntary third-party certification programs for foods and feeds (FDA, 2009a). In this document, it is clearly stated that industry has the primary responsibility to ensure that food products are safe and meet FDA requirements. The document outlines recommendations for third-party certification programs such as qualifications and training for auditors including coursework and field training. These recommendations, though helpful, are not "legally established responsibilities" and the extensive use of the word "should" in the document infers a recommendation rather than a requirement (FDA, 2009a).

Third-party audits are only one performance indicator and need to be supplemented with microbial testing, second-party audits of suppliers and the in-house capacity to meaningfully assess the results of audits and inspections. Any and all raw product suppliers should be included in the audit scope. More effective audit systems incorporate unannounced visits along with supplemental information into their framework and require extensive documentation of internal audits, regulatory compliance, laboratory results and raw product certifications.

Preventive measures such as instilling and enhancing a food safety culture, where there are shared values throughout the organization that support risk-reduction, may improve the safety of the food supply by supplying daily reminders, incentives and food safety priorities in the absence of inspectors or auditors. Improving and encouraging communication with front-line employees - any food producer is only as good as its worst front-line staff - can help mitigate high-risk situations such as at PCA, where employees said the facility was "a dump," but did not report their concerns to officials before people became ill and died (Sharp, 2009). Audits, regulatory inspections and testing are an important part of the food safety system, but alone and individually they are not enough.

Education and training are the focus of many food handling behavior interventions. However, research suggests that the impacts of food handler training programs are 
often inconsistent, and program evaluation is rarely conducted (Almanza \& Nesmith, 2004; Egan et al., 2007; Frash et al., 2005; Roberts et al., 2008). Measuring knowledge change is a poor indicator of changes in practices. Yiannas (2008) points out the limitations of focusing entirely on training as food safety culture indicators and suggests training is just one factor of a good organization. Conscientious proprietors provide training and proper tools, remove barriers, and proceed with a focus on positive food safety behavior. The lack of food safety expertise within an organization to effectively evaluate and interpret audit or inspection results may compound problems. Standards applied by auditing firms and regulatory inspections often include training as a component, but outbreak history suggests that little evaluation of effectiveness is explored.

Researchers have suggested that the only reliable measure of effectiveness of food safety culture-supporting intervention material is through the observation of food preparation practices (Redmond and Griffith, 2003; Anderson et al., 2004; Redmond et al., 2004; Chapman et al., 2010).

In 2010, beef processor JBS started a trial using video cameras as part of their thirdparty monitoring and auditing efforts (Crews, 2011). Strategically placed cameras recorded footage that could then be observed by auditors around-the-clock and random audits could then be conducted remotely. Not only does this allow for immediate feedback, it has also proven an effective training tool for employees, as they can observe and learn from watching themselves at work (Crews, 2011). Improvement at the pilot plant was seen in days instead of months and compliance rates consistently exceeded 99\%. Errors can be addressed almost immediately before problems develop (Crews, 2011).

Assessing food-handling practices of staff through internal observations, externally-led evaluations, and audit and inspection results can provide indicators of a food safety culture. Results of these evaluations can be used to modify interventions and further improve the organization's culture of food safety (Mitchell et al, 2007).

332

Since most commercial food establishments are audited or inspected, it remains likely that any food establishment that becomes associated with a foodborne illness outbreak will have had some type of audit in the past. Audits still do not guarantee safe food and have inherent limitations based upon stakeholder involvement, auditor competence, audit scope, and audit system.

In August 2008, Listeria monocytogenes-contaminated deli meats produced by Maple Leaf Foods, Inc. of Canada caused 57 illnesses and 22 deaths (Weatherill, 2009). A panel of international food safety experts convened by Maple Leaf Foods, Inc. to investigate the source of the deli meat contamination determined that the most probable contamination source was mechanical meat slicers that, despite cleaning according to the 
manufacturer's instructions, had meat residue trapped deep inside the slicing mechanisms (Weatherill, 2009). An independent investigative review commissioned by the Canadian federal government concluded that the focus on food safety was insufficient among senior management at both the company and the various government organizations involved before and during the outbreak; that insufficient planning had been undertaken to be prepared for a potential outbreak; and that those involved lacked a sense of urgency at the outset of the outbreak (Mason, 2009).

The specific plant linked to the outbreak received satisfactory marks from federal inspectors for complying with federal regulatory requirements. They appeared to be doing everything right. Employees consistently addressed instances of non-compliance when they were identified. The plant's management maintained all required records, ensured that staff training took place, and ensured the established quality assurance program was followed. At all plants, the company conducted environmental testing that went beyond regulatory requirements (Weatherill, 2009). Prior to the outbreak, Maple Leaf Foods, Inc. conducted more than 3,000 environmental tests annually at the implicated plant and tested products monthly (McCain, 2009). Although no product tests revealed the presence of Listeria spp., a number of environmental samples detected the bacteria in the months before the public was alerted in August to possible contamination (CFIA, 2009; McCain, 2009). However, the company failed to recognize and identify the underlying cause of a sporadic yet persistent pattern of environmental test results that were positive for Listeria spp. and was not obliged to report these results.

The use of audits to help create, improve, and maintain a genuine food safety culture holds the most promise in preventing foodborne illness and safeguarding public health. A common thread in all of the outbreaks described above is a clear lack of food safety culture among the implicated companies. In the E. coli outbreak in South Wales, a public inquiry into the outbreak by Professor Hugh Pennington (2009) found that, in addition to allowing cross contamination through the operation's single vacuum packaging machine, butcher William Tudor encouraged ill employees to continue working in establishments and preparing meat for sale. Upon review of statements made by employees and environmental health officers to the police, of video and photographic evidence, and of management documentation, Professor Chris Griffith (2010), head of the food research and consultancy unit at the University of Wales Institute, Cardiff, told the inquiry the culture at the premises was one of little regard for the importance of food safety but where making and saving money was the priority. Health code violations at the abattoir were longstanding, repetitive and widely known among environmental health officers responsible for inspecting the operation. Although foodborne illness may not always be completely preventable, that the risk of a business causing foodborne illness is, to a large extent, a consequence of its own activities. Audit and inspection information must be leveraged into corrective actions to mitigate risk. 
375 Food safety culture, not only within the company but also within a supply chain should also be emphasized. In both the Odwalla and PCA outbreaks, second-party audits were able to identify problems the third party auditors did not. Open communication between suppliers and buyers including expectations and risk management practices is essential. Systems where retailers work with their suppliers to help them achieve objectives have had somewhat better buy-in from suppliers and may achieve better results because they reinforce that culture. (Rains, 2009; Steir, 2009).

Third-party auditing is a business, where an organization or business pays another firm to verify whether a supplier is following agreed-upon standards. While third-party auditors are not in the same position as regulatory inspectors with respect to policing an industry - they can provide information upon which buyers can make decisions. Based on historic examples, audit results have not been well understood by requiring buyers (Griffith, 2010; Schmit, 2009). It is incumbent on auditing firms and food businesses commissioning audits to understand the strengths and limitations of any evaluation process. Companies who blame the auditor or inspector for outbreaks of foodborne illness should also blame themselves.

References

Acheson, D. (2010.) Opportunities for private third party auditors. Leavitt Partners Blog. Retrieved June 21, 2010 from: http:/ /leavittpartnersblog.com/2010/06/opportunities-for-private-third-partyauditors/.

AIB International. (2007). The value of third party audits. Retrieved August 11, 2011 from https://www.aibonline.org/press/ValueofThirdPartyAudits.html.

Almanza, B. A. \& Nesmith, M. S. (2004). Food safety certification regulations in the United States. Journal of Enrvironmental Health, 66, 10-14.

Anderson, J. B., Shuster, T.A., Hansen, K.E., Levy, A.S. \& Volk, A. (2004). A camera's view of consumer food-handling behaviors. Journal of the American Dietetic Association, 104, 186-191.

Australia New Zealand Food Authority (ANZFA). (2001). Food safety: An audit system. Retrieved August 11, 2011 from http://www.foodstandards.gov.au/_srcfiles/FS_Audit_Report_final\%20edit0702.pdf.

417 http://www.wageningenacademic.com/_clientFiles/download/EIFL-06-e.pdf 
California Food Emergency Response Team (CalFERT). (2007). Investigation of an Escherichia coli O157:H7 outbreak associated with Dole pre-packaged spinach. Retrieved November 6, 2011 from http:/ /www.marlerclark.com/2006_Spinach_Report_Final_01.pdf

CanadaGAP, 2012. CanadaGAP. Retrieved March 19 from: http://www.canadagap.ca/

Canadian Food Inspection Agency. (2009). Lessons learned: The Canadian Food Inspection Agency's review of Est. 97B (Maple Leaf Consumer Foods Inc.). Retrieved April 22, 2009, from

http:/ / www.inspection.gc.ca/english/agen/eval/listeria2/listeria2e.shtml

Centers for Disease Control and Prevention. (2009a). 2008 - 2009 Salmonella http:/ / www.cdc.gov/salmonella/typhimurium/SalmonellaTyphimuriumAAR.pdf.

Centers for Disease Control and Prevention. (2009b). Multistate outbreak of Salmonella infections associated with peanut butter and peanut butter-containing products United States, 2008-2009. Morbidity and Mortality Weekly Report, 58(4), 1-6. communication intervention (evaluation of tools). Journal of Food Protection, 73(6), 11014431107. Company of hardworking Lynchburg, Va., CEO has faced trouble before. The Atlanta Journal-Constitution. Retrieved June 26, 2010, from http://www.ajc.com/services/content/news/stories/2009/02/08/peanutcorp0208.ht $\mathrm{ml}$

Costa, R. (2010.) The food safety inspection party. Food Safety and Environmental Health Blog. Retrieved August 11, 2011 from

http:/ / www.safefoodsblog.com/2010/10/articles/food-safety/the-food-safetyinspection-party/.

458 http:/ / www.safefoodsblog.com/2011/10/articles/farm-to-fork/the-role-of-the-third- 
461 Crews, J. (2011). JBS plays a leading role in advancing food safety with third-party

462 remote video auditing. Meat \& Poultry. Retrieved August 11, 2011 from

463 http://www.meatpoultry.com/Writers/Joel\%20Crews/Action.aspx?LoggedIn=true\&E 464 mailKey=dpowell@ksu.edu.

Cruz M.A, Katz D.J and Suarez J.A. (2001). An assessment of the ability of routine restaurant inspections to predict food-borne outbreaks in Miami-Dade County, Florida. Am J Public Health 91, 821-823.

DeNucci, A. J. (2007). Independent state auditor's report on certain activities of the

Department of Public Health Food Protection Program (July 1, 2003 Through December 31, 2005), March 26. Boston: Auditor of the Commonwealth.

Doering, R. (2010). The food safety risk of imported food. Food Law. Retrieved December 21, 2010 from http://www.gowlings.com/KnowledgeCentre/PublicationPDFs/20101221_FoodSafety-Risk-of-Imported-Food_Ronald-Doering.pdf. (2007). A review of food safety and food hygiene training studies in the commercial sector. Food Control, 18, 1180-1190.

Frash, R. Binkley, M., Nelson, D. \& Almanza, B. (2005). Transfer of training efficacy in U.S. food safety accreditation. Journal of Culinary Science and Technology, 4, 7-38.

GFSI. (2012). Welcome to the Global Food Safety Initiative. Retrieved March 19 from: http://www.mygfsi.com/

Griffith, C. J. (2010). Do businesses get the food poisoning they deserve: The importance of food safety culture? British Food Journal, 112(4), 416-425.

IRCA, (2005). Food Safety Management Systems Internal Auditor Training. Retrieved March 16, 2012 from: www.irca.org/downloads/irca2190.pdf

501

Jones T.F., Pavlin B.L., LaFleur B.J., Ingram L.A. and Schaffner W. (2004). Restaurant inspection scores and foodborne disease. Emerging Infectious Diseases, 10, 688-692.

502 
503 Mahshie, A. (2009). Industry calls for changes to third-party audits. The Packer.

504 Retrieved August 11, 2011 from http:/ / www.thepacker.com/fruit-vegetable-

505 news/fresh-produce-handling-distributing/industry_calls_for_changes_to_third-

506 party_audits_122077334.html?email=yes\&cmntid=.

507

508

Mason, C. (2009). Listeriosis probe identifies multiple deficiencies. Canadian Medical

509 Association Journal, 181(5), E88-E89.

510

511

512

513

514

515

516

517

518

519

520

521

522

523

524

525

526

527

528

529

530

531

532

533

534

535

536

Martin, A. (2009). Peanut plant says audits declared it in top shape. New York Times.

Retrieved August 11, 2011 from

http://www.nytimes.com/2009/02/05/business/05peanuts.html?_r=1\&adxnnl=1\&ad xnnlx=1316750755-bWxLUm2opEwrd3zcePBOcg.

McCain, M. (2009). Follow-up statement on subcommittee appearance. Our Journey to Food Safety Leadership Blog. Retrieved April 21, 2009, from

http:/ / blog.mapleleaf.com/2009/04/follow-up-statement-on-subcommitteeappearance- 123

Mitchell, R., Fraser, A. \& Bearon, L. (2007). Preventing food-borne illness in food service establishments: Broadening the framework for intervention and research on safe food handling behaviors. International Journal of Environmental Health Research, 17, 9-24.

Moss, M. \& Martin, A. (2009). Food problems elude private inspectors. New York Times. . Retrieved August 25, 2011 from

http:/ /www.nytimes.com/2009/03/06/business/06food.html?_r=1\&adxnnl=1\&partne $\mathrm{r}=\mathrm{rss} \& \mathrm{emc}=\mathrm{rss} \&$ pagewanted $=1 \&$ ad $x n n l \mathrm{x}=1313351697-\mathrm{g} 4 \mathrm{x}+\mathrm{BvK}+\mathrm{p} 9 / \mathrm{t} 4 \mathrm{GNMd}+7 \mathrm{mIw}$

537 Powell, D.A., Jacob, C.J. and Chapman, B. (2011). Enhancing food safety culture to 538 reduce rates of foodborne illness. Food Control. 22(6): 817-822.

539 Powell, D.A., Jacob, C.J. and Chapman, B. (2009). Produce in public: Spinach, safety and 540 public policy in Microbial Safety of Fresh Produce: Challenges, Perspectives, and

541 Strategies. In X. Fan, B.A. Niemira, C.J. Doona, F.E. Feeherry and R.B. Gravani (Eds.),

542 Blackwell Publishing, (pp. 369-384).

543

544 Powell, D.A. and Leiss, W. (1997). Mad Cows and Mothers' Milk. McGill-Queen's

545 University Press. (pp. 308). 
Prevor, J. (2011a). Cantaloupe crisis analysis: While "blame the auditor" frenzy rages, it

548 pays to look at best practices vs standard practices. Perishable Pundit. Retrieved

549 October 10, 2011 from

550 http://www.perishablepundit.com/index.php?date=10/23/11\#2

551

552

553

Prevor, J. (2011b). When it comes to audits... retailers get what they specify. Perishable

554

555

556

557 Pundit. Retrieved October 10, 2011 from

http:/ / www.perishablepundit.com/index.php?date=10/23/11\#4

558 http://barfblog.foodsafety.ksu.edu/blog/148109/11/05/04/food-safety-auditing-

559 about-safety-or-money-gfsi-light.

560

561

562

Quester, B. \& Mento, T. (2011). Salmonella outbreak traced to cantaloupes in

563

Guatemala. News21. Retrieved October 10, 2011 from

564

565

566

http://foodsafety.news21.com/2011/imports/cantaloupe.

Raine, G. (1998). U.S. Army Declined to Carry Odwalla. San Francisco Examiner. Retrieved December 12, 2011 from

http://www.marlerclark.com/case_news/detail/us-army-declined-to-carry-odwalla.

571

572

573

574

Rains, B.D. (2009). Process Safety Management. What is the right audit approach for you? Dupont Safety Resources. Retrieved March 19, 2012

from: http://www2.dupont.com/Sustainable_Solutions/en_US/assets/downloads/Pr ocessSafetyManagement_AuditApproach.pdf

575

576

577

578

579

580

581

582

583

584

585

586

587

Redmond, E. C. \& Griffith, C. J. (2003). A comparison and evaluation of research methods used in consumer food safety studies. International Journal of Consumer Studies, 27(1), 17-33.

Redmond, E., Griffith, C.J., Slader, J., Humphrey, T. (2004), Microbiological and observational analysis of cross contamination risks during domestic food preparation, British Food Journal, 106, 581-97.

Roberts, K. R., Barrett, B. B., Howells, A. D., Shanklin, C. W., Pilling, V. K. \& Brannon, L. (2008). Food safety training and foodservice employees' knowledge and behavior. Food Protection Trends, 28, 252-260.

Schmit, J. (2009). Broken links in food-safety chain hid peanut plants' risks. USA Today. Retrieved August 11, 2011 from 
588 http://www.usatoday.com/money/industries/food/2009-04-26-peanuts-salmonellafood-safety_N.htm.

Schneider, C. (2009). Peanut Corp. of America did sell to retailers. The

592 Atlanta Journal-Constitution. Retrieved June 26, 2010, from http://www.ajc.com/news/content/metro/stories/2009/02/09/georgia_peanut_retai 594 1.html

Sharp, T. (2009). AIB responds to accusations of potential link to Salmonella outbreak. Kansas State Collegian. Retrieved August 11, 2011 from

598 http://www.kstatecollegian.com/aib-responds-to-accusations-of-potential-link-tosalmonella-outbreak-1.1713506\#.TnwFXk_9qoV.

Steir, R.F. (2009) Third party audits: What the food industry really needs. Food Safety

602 Magazine. October/November. Retrieved March 19, 2012 from:

603

604

605 http:/ / www.foodsafetymagazine.com/article.asp?id=3383\&sub=sub1

Sun, L. (2009). Conflicts of interest mar food producers' independent inspections. Washington Post. Retrieved August 11, 2011 from

608 dyn/content/article/2010/10/21/AR2010102106900.html.

U.S. Food and Drug Administration (2011). Environmental Assessment: Factors a Multi-State Outbreak of Listeriosis Retrieved March 17, 2011 from:

613 http://www.fda.gov/Food/FoodSafety/FoodborneIllness/ucm276247.htm http://www.fda.gov/RegulatoryInformation/Guidances/ucm125431.htm\#VH.

U.S. Food and Drug Administration. (2009b). Peanut butter and other peanut containing products recall list. Retrieved June 26, 2010, from http://www.accessdata.fda.gov/scripts/ peanutbutterrecall/index.cfm product recall. Retrieved August 25, 2011 from 
632 U.S. Government Accountability Office. (2008). Selected countries' systems can offer 633 insights into ensuring import safety and responding to foodborne illness. Retrieved 634 November 19, 2011 from http:/ / www.gao.gov/new.items/d08794.pdf

635

636 Weatherill, S. (2009). Report of the independent investigator into the 2008 listeriosis

637 outbreak. Government of Canada. Retrieved June 20, 2010, from

638 http://www.listeriosis-listeriose.investigation-

639 enquete.gc.ca/index_e.php?s1=rpt\&page=tab

640

641 Weise, E. (2010). Food safety auditors are often paid by the firms they audit. USA

642 Today. Retrieved August 11, 2011 from

643 http://www.usatoday.com/yourlife/food/safety/2010-10-01-foodaudits01_ST_N.htm.

644

645 Yiannas, F. (2008). Food safety culture: Creating a behavior-based food safety management

646 system. New York: Springer Science. Book description retrieved September 28, 2007

647 from http://www.springer.com/dal/home/life+sci/food+science?SGWID=1-40723-

648 22-173741407-0 
1 Audits and inspections are never enough: a critique to enhance food safety

3 Powell, D.A., Erdozain, S., Dodd, C., Costa, R. Morley, K. and Chapman, B.J.

4

5 Douglas Powell

6 Professor, Food Safety

7 Department of Diagnostic Medicine/Pathobiology

8 Kansas State University

9 Manhattan, KS 66506

11 Maria Sol Erdozain

12 Research Assistant

13 Kansas State University

14 Manhattan, KS 66506

$15 \quad 785-323-7501$

17 Charles Dodd

18 cdoddemail@googlemail.com

20 Katija Morley

21 Research Assistant

22 Kansas State University

2322 Karen Ave. Guelph, ON N1G 2N9. 519-362-0101

24 Tija.morley@gmail.com

25

26 Roy E. Costa

27 President

28 Environ Health Associates, Inc

292694 Magnolia Rd

30 Deland Fla 32720

$31 \quad 386-734-5187$

32 Rcosta1@cfl.rr.com

33

34 Benjamin Chapman

35 Assistant Professor

36 Department of 4-H Youth Development and Family \& Consumer Sciences

37 North Carolina State University, NC Cooperative Extension

38 Raleigh, North Carolina

3927616

40

41

42 Keywords: food safety; audit; inspection; culture 
Abstract

Internal and external food safety audits are conducted to assess the safety and quality of food including on-farm production, manufacturing practices, sanitation, and hygiene. Some auditors are direct stakeholders that are employed by food establishments to conduct internal audits, while other auditors may represent the interests of a secondparty purchaser or a third-party auditing agency. Some buyers conduct their own audits or additional testing, while some buyers trust the results of third-party audits or inspections. Third-party auditors, however, use various food safety audit standards and most do not have a vested interest in the products being sold. Audits are conducted under a proprietary standard, while food safety inspections are generally conducted within a legal framework. There have been many foodborne illness outbreaks linked to food processors that have passed third-party audits and inspections, raising questions about the utility of both. Supporters argue third-party audits are a way to ensure food safety in an era of dwindling economic resources. Critics contend that while external audits and inspections can be a valuable tool to help ensure safe food, such activities represent only a snapshot in time. This paper identifies limitations of food safety inspections and audits and provides recommendations for strengthening the system, based on developing a strong food safety culture, including risk-based verification steps, throughout the food safety system.

\subsection{Introduction}

Billions of meals are prepared safely each day throughout the world. Much of that food is deemed safe by some form of verification of practices, known commonly in the commercial food system as external audits or inspection. Yet when outbreaks of foodborne illness happen, the results can be emotionally, physically and financially devastating to the victims and the businesses involved. Many outbreaks involve firms that have had their food production systems verified and received acceptable ratings from food safety auditors or government inspectors.

Food safety audits and inspections are one activity used to verify that a food producer or individual is following specific guidelines, requirements or rules. Audits involve a "systematic and independent examination to determine whether quality/safety activities and related results comply with planned arrangements and whether these arrangements are implemented effectively and are suitable to achieve objectives" (ANZFA, 2001; ANZFA was later morphed into Food Standards Australia New Zealand). Planned arrangements, as defined by the Australia New Zealand Food Authority are commonly referred to as standards within the food industry. The difference between inspections and audits is that an inspection evaluates "conformity by measuring, observing, testing or gauging the relevant characteristics" (ANZFA, 2001). Audits may be supplemented with microbiological and quality assurance product testing and process inspections by regulatory agencies or industry to help ensure adherence to recognized regulations and good manufacturing practices. 
Reactive investigations based on direct consumer complaints or concerns raised through social media may provide additional information.

89

90

91

92

93

94

95

96

97

98

99

100

101

102

103

104

105

106

107

108

109

110

111

112

113

114

115

116

117

118

119

120

121

122

123

124

125

126

127

128

129

An audit of food safety practices, facilities, documentation and written procedures is used to gather information regarding food production and processing practices being followed by a particular producer, identifying areas for improvement and areas that are deficient (ANZFA, 2001). Audit reports, in theory, serve as the "eyes and ears" for an organization buying food from a supplier (Weise, 2010). There are several types of audits, and a variety of audit organizations, each with their own unique or common food safety guidelines.

Self-audits are internal audits performed by a food establishment itself. These businesses usually have a quality assurance team that leads the internal audits. These internal audits may have good potential for reducing risk if the methods followed are those outlined in widely accepted codes and risk assessment guidance documents. Second-party audits are audits that a downstream company, or buyer, performs on their supplier. Third-party audits are performed by an outside firm that usually focuses entirely on verification or standard implementation to ensure that a buyer's rules are being followed (Costa, 2010). Third-party audits examine compliance with laws and codes of practice as well as provide "insight into management controls and supervision" (Costa, 2010).

\subsection{The role of audits in food safety}

Third-party audits are one part of a multi-factorial approach to food safety. The popularity of third-party audits has increased corresponding to a shift in food safety governance away from government regulation and inspection towards the development of private food safety standards (Busch, 2011). Standard setting organizations (e.g. International Organization for Standardization (ISO) and the British Retail Consortium (BRC)) include industry consortia, private voluntary associations and buyers. There are many different food safety standards available to food producers and manufacturers even within a single industry segment. While the various standards are voluntary, demand by buyers essentially makes certification or verification under these standards de facto mandatory for food companies that want to continue to sell their product to major retailers (Busch, 2011). This has created a system for enforcing food safety standards with little burden on taxpayers.

Costa (2010) argues that third-party audits should focus on strengthening self-audit methods and operational controls to achieve safer food and maximize benefits. The U.S. Government Accountability Office (GAO) noted in a 2008 report that, while inspectors or auditors play an active role in overseeing compliance, the burden for food safety lies primarily with food producers (GAO, 2008). For example, Prevor (2011b) argues that if a company such as Walmart wanted specific standards for a product, even if it exceeded 
U.S. Food and Drug Administration (FDA) standards, the company would demand that from the auditor -- and get it. Doering (2010) has also said responsibility for verification primarily lies with industry, given that inspection efforts, even if doubled, would not be enough to make sure every food item is safe. Third-party audits provide the data upon which certification and buying decisions are made, and are now a popular choice for retailers who use them to push the responsibility (and costs) for food safety and quality back on to the supplier (Steir, 2009).

Third-party audits are relied upon within a single company or supply chain for a number of reasons. For some, it is a genuine desire to improve food safety, quality and sanitation or a way to solve/troubleshoot existing problems (Steir, 2009). For others it is a potential marketing advantage or a customer requirement. The effectiveness of these audits may link to the motivation behind the audit. It has been determined that creating a food safety culture is imperative to an effective food safety risk management system (Powell et al., 2011; Yiannas, 2008). Companies with a strong food safety culture may be more likely to obtain a third party audit because they want to improve operations, not just because of customer demand. Companies with a strong food safety culture are also likely to use audit results as guidance and opportunity to improve their practices. Audits -- first- second- or third-party -- are another tool for companies to enhance safe food production.

What is not clear is the role of third party audits in reducing the risk of contaminated food reaching the marketplace and the ability of auditors to identify problems or high risk operations. The utility of third party audits has been examined in other industries as well. A 10-year study on workplace safety on U.S. railroads found that high audit scores partially correlated with improved legislative compliance but did not necessarily correspond to improved safety performance (Peterson, 2001). This indicated there were problems somewhere in the system and that the audit process was not necessarily valid for that industry.

\subsection{Limitations of audits}

Audit systems, in their current form, have limitations in improving food safety. There are no current empirical evaluations that look at the correlation between audit scores and foodborne illness outbreaks but there is a long and storied history of food safety failures involving third-party audits and inspections.

172

Third-party audits are analogous in many ways to regulatory municipal inspections of foodservice operations: the effectiveness of both audits and inspections is driven largely by observational judgment and consistency of the inspector or auditor. Foodservice inspection is a cornerstone of local public health, yet inspection scores can be poor predictors of foodborne illness. Jones and colleagues (2004) examined over 160,000 inspections in Tennessee over 7 years and found no difference between scores of 
173 foodservices associated with outbreaks and those that were not. Similar results were

174 previously found in Miami-Dade county (Cruz et al., 2001). In Massachusetts,

175 researchers found that jurisdictions had different inspection criteria, and even within a given jurisdiction, a risk to one inspector may not be a risk to another (DeNucci 2007).

Many foodborne illness outbreaks have been linked to farms, processors and retailers that went through some form of audit certification. The January 2009 outbreak of Salmonella Typhimurium linked to the Peanut Corporation of America (PCA) has been frequently cited as an example of a failure in the third party auditing system (Busch, 2011; Steir, 2009; Moss and Martin, 2009). In January, 2009 PCA recalled over 3,900 peanut butter and other peanut-containing products from more than 350 companies (FDA, 2009b), 691 people were sickened and nine died across 46 U.S. states and in Canada (CDC, 2009a).

Moss and Martin (2009) reported in the New York Times that an auditor with AIB was responsible for evaluating the safety of products produced by PCA. The peanut company knew in advance when the auditors were arriving. "The overall food safety level of this facility was considered to be: SUPERIOR," the auditor concluded in his March 27, 2008, report for AIB. A copy of the audit was obtained by the Times. AIB was not alone in missing the trouble at the PCA plant in Blakely, Georgia. State inspectors also found only minor problems. This outbreak and others highlight some of the limitations of both third party audits and government inspections which are included in Table I below.

The Global Food Safety Initiative (GFSI) is a non-profit foundation managed by the consumer goods forum (GFSI, 2012) and was launched in May 2000 as a response to the growing number of private standards. GFSI is a benchmarking system where "all recognized schemes have a common foundation of requirements which should provide consistent results, in regard to the common requirements applied during the audit, but the benchmarked schemes cannot be considered as equal" (GFSI, 2012). One objective of the initiative is to reduce costs within the system by reducing the number of different audits a firm requires for their different customers. The success of the GFSI approach has not been evaluated to date.

Some auditing companies and standards owners are trying to prevent situations where a company may have a food safety problem but still obtain a passing grade, through the application of mandatory or automatic failures (Steir, 2009). The use of auto-failures in an audit is becoming more common. High-risk activities are identified, such as the quality of water used for washing fresh produce, and if the producer is not compliant with those items, they fail the audit regardless of the final score. Many standards also allow the auditor to suggest an auto-failure if they identify and document any situation they deem to be an immediate food safety risk (CanadaGAP, 2012). 
218 Government inspectors have also failed to prevent foodborne illness outbreaks. Fiveyear-old Mason Jones was one of 157 people - primarily children - who became ill in an outbreak in South Wales caused by Escherichia coli O157:H7 in September 2005. The outbreak was traced to the consumption of cooked meats provided to schools by John Tudor \& Son, a catering butcher business. A packaging machine at the business, used for both raw and cooked meats, was identified as the probable source of contamination - where E. coli O157:H7 was most likely transferred from raw meat to cooked meat and was then distributed to four authorities in South Wales for their school meal programs. Ultimately, 31 people were admitted to hospital and, tragically, Mason Jones died.

Following the Wales outbreak, a number of mistakes and shortcomings by environmental health officers were identified - which in no way lessened the primary responsibility on the supplier of contaminated food -- including the failure of one officer to verify claims that all food handlers had food hygiene certificates and the failure by another to insist that steps be taken to prevent cross contamination between raw and cooked meats during vacuum packaging (Pennington, 2009). Brian Curtis, a retired senior U.K. Food Standards Agency official, told the inquiry that the Hazard Analysis Critical Control Point (HACCP) plan reportedly used by John Tudor \& Son, and reviewed by Mr. Curtis at the time of the inquiry, would not ensure the production of safe food. Mr. Curtis faulted environmental health officers for failing to identify the deficiencies and weaknesses in the HACCP plan, and for failing to identify and address the poor hygiene and unsafe food handling practices at the facility. In addition, utilizing announced, as opposed to unannounced, inspections allowed the butcher to falsify backlogged cleaning records before such records were due to be viewed by environmental health officers (Pennington, 2009).

In Sept. 2006, 199 people were sickened and at least three died from consumption of bagged spinach contaminated with E. coli O157:H7 and produced by Earthbound Farms of California. Samples of river water, wild pig feces, and cattle feces from a nearby grass-fed cattle operation tested positive for the outbreak strain of E. coli O157:H7 (California Food Emergency Response Team, 2007). Following the outbreak it was revealed that the suspect facilities had received a third-party audit of their good agricultural practices (GAPs) from auditor Primus Labs that did not raise concerns for the buyer, Dole Foods, to alter any purchasing decisions. This was the $29^{\text {th }}$ documented outbreak of foodborne illness involving leafy greens in the U.S. Despite decades of letters and pleading by regulators to the industry to improve microbiological safety standards, there was no verification that farmers and others in the farm-to-fork food safety system were seriously incorporating and acting on risk reduction messages, especially in production fields rather than just processing facilities (Powell et al., 2009). 


\subsection{Improving audits and inspections}

Food safety auditors and inspectors are an integral part of the food safety system, and their use will expand in the future, for both domestic and imported foodstuffs. Supporters of third-party audits argue this type of audit augments the efforts of food regulatory agencies, such as FDA, the Canadian Food Inspection Agency (CFIA), and others.

Auditing can be helpful, in theory. Audit reports, are only useful if the purchaser who requires them reviews the results, understands the risks addressed by the standards and makes risk-reduction decisions based on the results. From past examples, there appears to be a disconnect between what auditors provide (a snapshot) and what buyers believe they are doing (a full verification of product and process).

Third-party auditing can also assist regulatory agencies by providing the extra assessment and data a regulatory agency might not be able to collect as often as required - but only if the data is shared with regulatory agencies. Audits and inspections can assist in the development of a food safety culture by dictating criteria for the sale of goods (Acheson, 2010). The training component for employees is another use of audits in the daily implementation of food safety practices (AIB International, 2007). Third-party audits also provide "thousands of checks and balances to the food supply system with no direct cost to taxpayers" (AIB International, 2007). However, theory and practice can differ.

Critics see many problems with the general way third-party audits are currently conducted and have described them as the equivalent of "mail-order diplomas" (Moss \& Martin, 2009). As far as being the "eyes and ears" for a company buying from the audited supplier, many problems are apparently missed during visits (Weise, 2010). It is imperative for the food industry to aggressively take corrective actions and make third-party audits and inspections more meaningful, more accurate, and to fully enhance the safety of consumers.

In an effort to improve the third party audit system, FDA is working to establish accreditation programs under a new food safety law, to insure the quality of audits (Karst, 2011). FDA is also trying to make audit results accessible so they can analyze the results for effectiveness and reliability (Karst, 2011). FDA released guidance for industry in 2009 regarding voluntary third-party certification programs for foods and feeds (FDA, 2009a). In this document, it is clearly stated that industry has the primary responsibility to ensure that food products are safe and meet FDA requirements. The document outlines recommendations for third-party certification programs such as qualifications and training for auditors including coursework and field training. These 
extensive use of the word "should" in the document infers a recommendation rather than a requirement (FDA, 2009a).

Third-party audits are only one performance indicator and need to be supplemented with microbial testing, second-party audits of suppliers and the in-house capacity to meaningfully assess the results of audits and inspections. Any and all raw product suppliers should be included in the audit scope. More effective audit systems incorporate unannounced visits along with supplemental information into their framework and require extensive documentation of internal audits, regulatory compliance, laboratory results and raw product certifications.

Preventive measures such as instilling and enhancing a food safety culture, where there are shared values throughout the organization that support risk-reduction, may improve the safety of the food supply by supplying daily reminders, incentives and food safety priorities in the absence of inspectors or auditors. Improving and encouraging communication with front-line employees - any food producer is only as good as its worst front-line staff - can help mitigate high-risk situations such as at PCA, where employees said the facility was "a dump," but did not report their concerns to officials before people became ill and died (Sharp, 2009). Audits, regulatory inspections and testing are an important part of the food safety system, but alone and individually they are not enough.

Education and training are the focus of many food handling behavior interventions. However, research suggests that the impacts of food handler training programs are often inconsistent, and program evaluation is rarely conducted (Almanza \& Nesmith, 2004; Egan et al., 2007; Frash et al., 2005; Roberts et al., 2008). Measuring knowledge change is a poor indicator of changes in practices. Yiannas (2008) points out the limitations of focusing entirely on training as food safety culture indicators and suggests training is just one factor of a good organization. Conscientious proprietors provide training and proper tools, remove barriers, and proceed with a focus on positive food safety behavior. The lack of food safety expertise within an organization to effectively evaluate and interpret audit or inspection results may compound problems. Standards applied by auditing firms and regulatory inspections often include training as a component, but outbreak history suggests that little evaluation of effectiveness is explored.

Researchers have suggested that the only reliable measure of effectiveness of food safety culture-supporting intervention material is through the observation of food preparation practices (Redmond and Griffith, 2003; Anderson et al., 2004; Redmond et al., 2004; Chapman et al., 2010).

In 2010, beef processor JBS started a trial using video cameras as part of their thirdparty monitoring and auditing efforts (Crews, 2011). Strategically placed cameras 
recorded footage that could then be observed by auditors around-the-clock and random audits could then be conducted remotely. Not only does this allow for immediate feedback, it has also proven an effective training tool for employees, as they can observe and learn from watching themselves at work (Crews, 2011). Improvement at the pilot plant was seen in days instead of months and compliance rates consistently exceeded $99 \%$. Errors can be addressed almost immediately before problems develop (Crews, 2011).

Assessing food-handling practices of staff through internal observations, externally-led evaluations, and audit and inspection results can provide indicators of a food safety culture. Results of these evaluations can be used to modify interventions and further improve the organization's culture of food safety (Mitchell et al, 2007).

Since most commercial food establishments are audited or inspected, it remains likely that any food establishment that becomes associated with a foodborne illness outbreak will have had some type of audit in the past. Audits provide only a snap-shot of information and have inherent limitations based upon stakeholder involvement, auditor competence, audit scope, and audit system.

In August 2008, Listeria monocytogenes-contaminated deli meats produced by Maple Leaf Foods, Inc. of Canada caused 57 illnesses and 22 deaths (Weatherill, 2009). A panel of international food safety experts convened by Maple Leaf Foods, Inc. to investigate the source of the deli meat contamination determined that the most probable contamination source was mechanical meat slicers that, despite cleaning according to the manufacturer's instructions, had meat residue trapped deep inside the slicing mechanisms (Weatherill, 2009). An independent investigative review commissioned by the Canadian federal government concluded that the focus on food safety was insufficient among senior management at both the company and the various government organizations involved before and during the outbreak; that insufficient planning had been undertaken to be prepared for a potential outbreak; and that those involved lacked a sense of urgency at the outset of the outbreak (Mason, 2009).

The specific plant linked to the outbreak received satisfactory marks from federal inspectors for complying with federal regulatory requirements. They appeared to be doing everything right. Employees consistently addressed instances of non-compliance when they were identified. The plant's management maintained all required records, ensured that staff training took place, and ensured the established quality assurance program was followed. At all plants, the company conducted environmental testing that went beyond regulatory requirements (Weatherill, 2009). Prior to the outbreak, Maple Leaf Foods, Inc. conducted more than 3,000 environmental tests annually at the implicated plant and tested products monthly (McCain, 2009). Although no product tests revealed the presence of Listeria spp., a number of environmental samples detected the bacteria in the months before the public was alerted in August to possible 
contamination (CFIA, 2009; McCain, 2009). However, the company failed to recognize and identify the underlying cause of a sporadic yet persistent pattern of environmental test results that were positive for Listeria spp. and was not obliged to report these results.

Audit and inspection information must be leveraged into corrective actions in order to mitigate risk. However, the use of audits to help create, improve, and maintain a genuine food safety culture holds the most promise in preventing foodborne illness and safeguarding public health.

A common thread in all of the outbreaks described above is a clear lack of food safety culture among the implicated companies. In the E. coli outbreak in South Wales, a public inquiry into the outbreak by Professor Hugh Pennington (2009) found that, in addition to allowing cross contamination through the operation's single vacuum packaging machine, butcher William Tudor encouraged ill employees to continue working in establishments and preparing meat for sale. Upon review of statements made by employees and environmental health officers to the police, of video and photographic evidence, and of management documentation, Professor Chris Griffith (2010), head of the food research and consultancy unit at the University of Wales Institute, Cardiff, told the inquiry the culture at the premises was one of little regard for the importance of food safety but where making and saving money was the priority. Health code violations at the abattoir were longstanding, repetitive and widely known among environmental health officers responsible for inspecting the operation Although foodborne illness may not always be completely preventable, Griffith (2010) concluded that the risk of a business causing foodborne illness is, to a large extent, a consequence of its own activities.

Food safety culture, not only within the company but also within a supply chain should also be emphasized. In both the Odwalla and PCA outbreaks, second-party audits were able to identify problems the third party auditors did not. Open communication between suppliers and buyers including expectations and risk management practices is essential. Systems where retailers work with their suppliers to help them achieve objectives have had somewhat better buy-in from suppliers and may achieve better results because they reinforce that culture. (Rains, 2009; Steir, 2009).

Third-party auditing is a business, where an organization or business pays another firm to verify whether a supplier is following agreed-upon standards. While third-party auditors are not in the same position as regulatory inspectors with respect to policing an industry - they can provide information upon which buyers can make decisions. Based on historic examples, audit results have not been well understood by requiring buyers (Griffith, 2010; Schmit, 2009). It is incumbent on auditing firms and food businesses commissioning audits to understand the strengths and limitations of any evaluation process. Companies who blame the auditor or inspector for outbreaks of foodborne illness should also blame themselves. 
References

Acheson, D. (2010.) Opportunities for private third party auditors. Leavitt Partners Blog. Retrieved June 21, 2010 from: http:/ /leavittpartnersblog.com/2010/06/opportunities-for-private-third-partyauditors/.

AIB International. (2007). The value of third party audits. Retrieved August 11, 2011 from https:/ / www.aibonline.org/press/ValueofThirdPartyAudits.html. the United States. Journal of Enroironmental Health, 66, 10-14. view of consumer food-handling behaviors. Journal of the American Dietetic Association, 104, 186-191.

Australia New Zealand Food Authority (ANZFA). (2001). Food safety: An audit system. Retrieved August 11, 2011 from

http://www.foodstandards.gov.au/_srcfiles/FS_Audit_Report_final\%20edit0702.pdf. Food Law: Governing Food Chains through Contract Law, Self Regulation, private Standards, Audits and Certification Schemes. van der Meulen BMJ. (Ed.) Retrieved March 19, 2012 from:

http://www.wageningenacademic.com/_clientFiles/download/EIFL-06-e.pdf Inspection Agency's review of Est. 97B (Maple Leaf Consumer Foods Inc.). Retrieved April 22, 2009, from http://www.inspection.gc.ca/english/agen/eval/listeria2/listeria2e.shtml

Centers for Disease Control and Prevention. (2009a). 2008 - 2009 Salmonella

Typhimurium outbreak response after action report. Retrieved November, 2011 from http://www.cdc.gov/salmonella/typhimurium/SalmonellaTyphimuriumAAR.pdf.

Chapman, B., Eversley, T., Filion, K., MacLaurin, T. \& Powell, D. (2010). Assessment of food safety practices of food service food handlers (risk assessment data): Testing a communication intervention (evaluation of tools). Journal of Food Protection, 73(6), 11011107. 
475 Costa, R. (2010.) The food safety inspection party. Food Safety and Environmental Health Blog. Retrieved August 11, 2011 from http:/ / www.safefoodsblog.com/2010/10/articles/food-safety/the-food-safetyinspection-party/. Associates, Inc. Retrieved October 10, 2011 from http:/ / www.safefoodsblog.com/2011/10/articles/farm-to-fork/the-role-of-the-thirdparty-food-safety-auditor/

Crews, J. (2011). JBS plays a leading role in advancing food safety with third-party remote video auditing. Meat \& Poultry. Retrieved August 11, 2011 from http:/ / www.meatpoultry.com/Writers/Joel\%20Crews/Action.aspx?LoggedIn=true\&E mailKey=dpowell@ksu.edu. restaurant inspections to predict food-borne outbreaks in Miami-Dade County, Florida. Am J Public Health 91, 821-823.

DeNucci, A. J. (2007). Independent state auditor's report on certain activities of the Department of Public Health Food Protection Program (July 1, 2003 Through December 31, 2005), March 26. Boston: Auditor of the Commonwealth.

Doering, R. (2010). The food safety risk of imported food. Food Law. Retrieved December 21, 2010 from http://www.gowlings.com/KnowledgeCentre/PublicationPDFs/20101221_FoodSafety-Risk-of-Imported-Food_Ronald-Doering.pdf.

504 (2007). A review of food safety and food hygiene training studies in the 505 commercial sector. Food Control, 18, 1180-1190. efficacy in U.S. food safety accreditation. Journal of Culinary Science and Technology, 4, 7-38.

511 GFSI. (2012). Welcome to the Global Food Safety Initiative. Retrieved March 19 from:

512 http://www.mygfsi.com/ 
517 Jones T.F., Pavlin B.L., LaFleur B.J., Ingram L.A. and Schaffner W. (2004). Restaurant 518 inspection scores and foodborne disease. Emerging Infectious Diseases, 10, 688-692.

519

520

521

522

523

524

525

526

527

528

529

530

531

532

533

534

535

536

537

538

539

540

541

542

543

544

545

546

547

548

549

550

551

552

553

554

555

556

557

558

Karst, T. (2011). Third party audits find media scrutiny. The Packer. Retrieved October 10, 2011 from http://www.thepacker.com/opinion/fresh-talk-blog/Third-partyaudits-find-media-scrutiny-132240843.html

Mahshie, A. (2009). Industry calls for changes to third-party audits. The Packer.

Retrieved August 11, 2011 from http:/ / www.thepacker.com/ fruit-vegetablenews/fresh-produce-handling-distributing/industry_calls_for_changes_to_thirdparty_audits_122077334.html?email=yes\&cmntid=.

Mason, C. (2009). Listeriosis probe identifies multiple deficiencies. Canadian Medical Association Journal, 181(5), E88-E89.

Martin, A. (2009). Peanut plant says audits declared it in top shape. New York Times. Retrieved August 11, 2011 from

http://www.nytimes.com/2009/02/05/business/05peanuts.html?_r=1\&adxnnl=1\&ad xnnlx=1316750755-bWxLUm2opEwrd3zcePBOcg.

McCain, M. (2009). Follow-up statement on subcommittee appearance. Our Journey to Food Safety Leadership Blog. Retrieved April 21, 2009, from

http:/ / blog.mapleleaf.com/2009/04/follow-up-statement-on-subcommitteeappearance- 123

Mitchell, R., Fraser, A. \& Bearon, L. (2007). Preventing food-borne illness in food service establishments: Broadening the framework for intervention and research on safe food handling behaviors. International Journal of Environmental Health Research, 17, 9-24.

Moss, M. \& Martin, A. (2009). Food problems elude private inspectors. New York Times. . Retrieved August 25, 2011 from

http:/ / www.nytimes.com/2009/03/06/business/06food.html?_r=1\&adxnnl=1\&partne $\mathrm{r}=\mathrm{rss} \&$ emc $=\mathrm{rss} \&$ pagewanted $=1 \& \mathrm{ad} \times \mathrm{nnnl}=1313351697-\mathrm{g} 4 \mathrm{x}+\mathrm{BvK}+\mathrm{p} 9 / \mathrm{t} 4 \mathrm{GNMd}+7 \mathrm{mIw}$

Pennington, H. (2009). The public inquiry into the September 2005 outbreak of E. coli O157 in South Wales. Retrieved June 19, 2010, from http://wales.gov.uk/ecolidocs/3008707/reporten.pdf?skip=1\&lang=en

Peterson, D. (2001). The Safety Scorecard: Using Multiple Measures to Judge Safety System Effectiveness Retrieved March 19 from: http:/ / ehstoday.com/safety/ bestpractices/ehs_imp_34484/ 
559 Powell, D.A., Jacob, C.J. and Chapman, B. (2011). Enhancing food safety culture to

560 reduce rates of foodborne illness. Food Control. 22(6): 817-822.

561

562 Powell, D.A., Jacob, C.J. and Chapman, B. (2009). Produce in public: Spinach, safety and

563 public policy in Microbial Safety of Fresh Produce: Challenges, Perspectives, and

564 Strategies. In X. Fan, B.A. Niemira, C.J. Doona, F.E. Feeherry and R.B. Gravani (Eds.),

565 Blackwell Publishing, (pp. 369-384).

566

567 Prevor, J. (2011b). When it comes to audits... retailers get what they specify. Perishable

568 Pundit. Retrieved October 10, 2011 from

569 http://www.perishablepundit.com/index.php?date=10/23/11\#4

570

571

572

Pronk, I. (2011). Is food safety auditing about safety or money? GFSI-light?

573

574

575

576

577

578

579

580

581

582

583

584

585

586

587

588

589

590

Barfblog.com. Retrieved August 11, 2011 from

http://barfblog.foodsafety.ksu.edu/blog/148109/11/05/04/food-safety-auditing-

about-safety-or-money-gfsi-light.

Rains, B.D. (2009). Process Safety Management. What is the right audit approach for you? Dupont Safety Resources. Retrieved March 19, 2012

from: http://www2.dupont.com/Sustainable_Solutions/en_US/assets/downloads/Pr ocessSafetyManagement_AuditApproach.pdf

Redmond, E. C. \& Griffith, C. J. (2003). A comparison and evaluation of research methods used in consumer food safety studies. International Journal of Consumer Studies, $27(1), 17-33$.

Redmond, E., Griffith, C.J., Slader, J., Humphrey, T. (2004), Microbiological and observational analysis of cross contamination risks during domestic food preparation, British Food Journal, 106, 581-97.

591

592

593

594

595

596

597

598

599

Roberts, K. R., Barrett, B. B., Howells, A. D., Shanklin, C. W., Pilling, V. K. \&

Brannon, L. (2008). Food safety training and foodservice employees'

knowledge and behavior. Food Protection Trends, 28, 252-260.

600

Schmit, J. (2009). Broken links in food-safety chain hid peanut plants' risks. USA Today. Retrieved August 11, 2011 from

http://www.usatoday.com/money/industries/food/2009-04-26-peanuts-salmonellafood-safety_N.htm.

Sharp, T. (2009). AIB responds to accusations of potential link to Salmonella outbreak. Kansas State Collegian. Retrieved August 11, 2011 from 
601 http://www.kstatecollegian.com/aib-responds-to-accusations-of-potential-link-to602 salmonella-outbreak-1.1713506\#.TnwFXk_9qoV.

603

604 Steir, R.F. (2009) Third party audits: What the food industry really needs. Food Safety

605 Magazine. October/November. Retrieved March 19, 2012 from:

606 http://www.foodsafetymagazine.com/article.asp?id=3383\&sub=sub1

607

608 Sun, L. (2009). Conflicts of interest mar food producers' independent inspections.

609 Washington Post. Retrieved August 11, 2011 from

610 http://www.washingtonpost.com/wp-

611 dyn/content/article/2010/10/21/AR2010102106900.html.

612

613 U.S. Food and Drug Administration. (2009a). Voluntary third-party certification

614 programs for foods and feeds. Retrieved August 11, 2011 from

615 http://www.fda.gov/RegulatoryInformation/Guidances/ucm125431.htm\#VH.

616

617 U.S. Food and Drug Administration. (2009b). Peanut butter and other peanut containing

618 products recall list. Retrieved June 26, 2010, from

619 http://www.accessdata.fda.gov/scripts/peanutbutterrecall/index.cfm

620

621

622

U.S. Government Accountability Office. (2008). Selected countries' systems can offer

623

624

625 Weatherill, S. (2009). Report of the independent investigator into the 2008 listeriosis

626 outbreak. Government of Canada. Retrieved June 20, 2010, from

627 http://www.listeriosis-listeriose.investigation-

628 enquete.gc.ca/index_e.php?s1=rpt\&page=tab

629

630

631

632

633

634

635

636

637

Weise, E. (2010). Food safety auditors are often paid by the firms they audit. USA

Today. Retrieved August 11, 2011 from

http://www.usatoday.com/yourlife/food/safety/2010-10-01-foodaudits01_ST_N.htm.

Yiannas, F. (2008). Food safety culture: Creating a behavior-based food safety management system. New York: Springer Science. Book description retrieved September 28, 2007 from http:/ / www.springer.com/dal/home/life+sci/food+science?SGWID=1-4072322-173741407-0 
Table I - Limitations of Third Party Audits

\begin{tabular}{|l|l|l|}
\hline $\begin{array}{l}\text { Audit } \\
\text { Limitations }\end{array}$ & Summary & Example \\
\hline $\begin{array}{l}\text { A snapshot } \\
\text { in time }\end{array}$ & $\begin{array}{l}\text { Audits and inspections remain point-in-time } \\
\text { assessments that represent a small fraction of } \\
\text { food production time and volume. If conducted } \\
\text { properly and the results acted upon, audits can } \\
\text { reveal strengths and weaknesses in a food safety } \\
\text { program, but cannot guarantee future } \\
\text { performance. Further, auditors can only examine } \\
\text { what a company provides, although skilled } \\
\text { auditors know what to ask for and may be able } \\
\text { to identify clues to systemic problems. }\end{array}$ & $\begin{array}{l}\text { PCA outbreak, a federal team of } \\
\text { investigators later uncovered a } \\
\text { number of alarming signs at the } \\
\text { peanut plant including testing } \\
\text { records from the company itself } \\
\text { that showed Salmonella in its } \\
\text { products as far back as June 2007 } \\
\text { (Martin, 2009) }\end{array}$ \\
\hline
\end{tabular}




\begin{tabular}{|c|c|c|}
\hline $\begin{array}{l}\text { Reliance on } \\
\text { an effective } \\
\text { standard }\end{array}$ & $\begin{array}{l}\text { The audit is only as effective as the standard } \\
\text { against which the practices are being measured. } \\
\text { Standards must be evidence-based, designed to } \\
\text { address the commodity/product specific risks } \\
\text { and practices and responsive to changing } \\
\text { industry practices and new science as it becomes } \\
\text { available. }\end{array}$ & $\begin{array}{l}\text { Cantaloupe outbreak, July } 2011 . \\
\text { Previous research had focused on } \\
\text { Salmonella and current industry } \\
\text { standards may not be robust } \\
\text { enough to address risk from } \\
\text { Listeria. }\end{array}$ \\
\hline $\begin{array}{l}\text { Effective } \\
\text { audit tool }\end{array}$ & $\begin{array}{l}\text { The audit tool (or audit checklist) must be } \\
\text { valid. There is no scientific basis for } \\
\text { certification/validation in audits (Mahshie, } \\
\text { 2009). There is high variability in the quality } \\
\text { and reliability of audits and many different } \\
\text { types of audit tools that vary in length, } \\
\text { complexity, and style. A firm may pass some } \\
\text { audits but still have a food safety risk factor }\end{array}$ & $\begin{array}{l}\text { Salmonella in eggs, Iowa, } 2010 \text {, } \\
\text { lead to 2,000 illnesses and the } \\
\text { recall of } 500 \text { million eggs. DeCoster } \\
\text { received a superior rating from AIB } \\
\text { International, despite audit reports } \\
\text { that are typically } 10-20 \text { pages and } \\
\text { consider over } 300 \text { elements (AIB } \\
\text { International, 2007). }\end{array}$ \\
\hline $\begin{array}{l}\text { or } \\
\text { etence }\end{array}$ & $\begin{array}{l}\text { require paying attention and thin } \\
\text { individual ability of an auditor ha } \\
\text { impact on the outcome of the aud } \\
\text { party audits look for objective ev } \\
\text { compliance, but effective auditor } \\
\text { to assess risk, particularly in unic } \\
\text { and synthesize the information p } \\
\text { determine effectiveness of the foc } \\
\text { management system }\end{array}$ & $\begin{array}{l}\text { In the aftermath of the PCA } \\
\text { outbreak, the competency of both } \\
\text { the auditor and the auditing firm } \\
\text { were criticized. The auditor of the } \\
\text { PCA facility was an experienced } \\
\text { auditor but was an expert in fresh } \\
\text { produce and was not aware that } \\
\text { peanuts were susceptible to } \\
\text { Salmonella (Moss and Martin, } \\
\text { 2009) }\end{array}$ \\
\hline Aud & $\begin{array}{l}\text { dit scope must be broad enough to } \\
\text { all operations, locations and products. } \\
\text { a company is presented with different } \\
\text { quotes they often choose the cheapest } \\
\text { hich is more likely the one with less } \\
\text { time (Pronk, 2011). This reduces cost for } \\
\text { m requesting the audit, and reduces the } \\
\text { of the auditor to see all parts of a } \\
\text { ex operation as well as the possibility of } \\
\text { ditor finding instances of non- } \\
\text { iance. }\end{array}$ & $\begin{array}{l}\text { On June 28, 2007, Veggie Booty } \\
\text { snack food was linked to an } \\
\text { outbreak of Salmonella. The plant } \\
\text { that made Veggie Booty had } \\
\text { received a rating of "excellent" } \\
\text { from AIB International, raising } \\
\text { questions about the efficacy of } \\
\text { auditors and audits, which, in this } \\
\text { case and others, did not extend to } \\
\text { ingredient suppliers (Moss \& } \\
\text { Martin, 2009). }\end{array}$ \\
\hline $\begin{array}{l}\text { Co } \\
\text { Int }\end{array}$ & \multicolumn{2}{|c|}{$\begin{array}{l}\text { Almost all food producers/retailers require their suppliers to pay for their own audits. } \\
\text { A company receiving a poor audit may be unwilling to hire that auditor again. Even } \\
\text { with safeguards in place, auditing bodies still must rely on the honesty of their } \\
\text { auditors to declare potential conflicts }\end{array}$} \\
\hline Follow-up & \multicolumn{2}{|c|}{$\begin{array}{l}\text { Auditors have no legal authority and cannot demand records, embargo products or } \\
\text { close an operation (Costa, 2011). Neither the auditor nor the audited company is } \\
\text { required to report non-compliances, even automatic failures, to regulatory agencies. If } \\
\text { the buyer does not review the audit report closely, which is often the case (Prevor, } \\
2011 \text { a), they may never know that their supplier had a serious non-conformance. }\end{array}$} \\
\hline
\end{tabular}

